\title{
Influence of Annealing Temperature on the Characteristics of Ti-Codoped GZO Thin Solid Film
}

\author{
Tao-Hsing Chen and Tzu-Yu Liao \\ Department of Mechanical Engineering, National Kaohsiung University of Applied Sciences, Kaohsiung 807, Taiwan \\ Correspondence should be addressed to Tao-Hsing Chen; thchen@cc.kuas.edu.tw
}

Received 6 May 2013; Accepted 29 June 2013

Academic Editor: Sheng-Rui Jian

Copyright (C) 2013 T.-H. Chen and T.-Y. Liao. This is an open access article distributed under the Creative Commons Attribution License, which permits unrestricted use, distribution, and reproduction in any medium, provided the original work is properly cited.

\begin{abstract}
This study utilizes radio frequency magnetron sputtering (RF sputtering) to deposit GZO transparent conductive film and Ti thin film on the same corning glass substrate and then treats $\mathrm{GZO} / \mathrm{Ti}$ thin film with rapid thermal annealing. The annealing temperatures are $300^{\circ} \mathrm{C}, 500^{\circ} \mathrm{C}$, and $550^{\circ} \mathrm{C}$, respectively. Ti:GZO transparent conductive oxide (TCO) thin films are deposited on glass substrates using a radio frequency magnetron sputtering technique. The thin films are then annealed at temperatures of $300^{\circ} \mathrm{C}, 500^{\circ} \mathrm{C}$, and $550^{\circ} \mathrm{C}$, respectively, for rapid thermal annealing. The effects of the annealing temperature on the optical properties, resistivity, and nanomechanical properties of the Ti:GZO thin films are then systematically explored. The results show that all of the annealed films have excellent transparency ( $90 \%)$ in the visible light range. Moreover, the resistivity of the Ti:GZO films reduces with an increasing annealing temperature, while the carrier concentration and Hall mobility both increase. Finally, the hardness and Young's modulus of the Ti:GZO thin films are both found to increase as the annealing temperature is increased.
\end{abstract}

\section{Introduction}

Transparent conductive oxide (TCO) thin films are widely used in the optoelectronics field for such applications as flat panel display devices, thin film solar cells, touch panels, and antistatic windows [1-5]. TCO films are commonly fabricated using tin-doped indium oxide (ITO) since ITO has a low resistivity $\left(\sim 10^{-4} \Omega-\mathrm{cm}\right)$ and excellent transmittance in the visible region [6-9]. However, ITO is both expensive (due to the limited availability of indium) and toxic. As a result, the problem of finding suitable alternatives for ITO has emerged as a pressing concern in recent years.

Zinc oxide $(\mathrm{ZnO})$ has many favorable characteristics, including nontoxicity, low cost, high chemical and thermal stability, and good process integrability [10]. As a result, $\mathrm{ZnO}$ is regarded as a promising alternative to ITO in fabricating TCO thin-film structures. It has been shown that the electrical properties of $\mathrm{ZnO}$ can be enhanced by doping the lattice with aluminum $(\mathrm{Al})$, gallium $(\mathrm{Ga})$, or indium (In) [11]. Among these dopants, $\mathrm{Al}$ and Ga are particularly well suited to the fabrication of transparent conductive $\mathrm{ZnO}$ thin films because they contribute to electron conduction.
Al-doped $\mathrm{ZnO}$ thin films have high transmittance and low resistivity. However, Ga-doped $\mathrm{ZnO}$ thin films offer a number of practical advantages over Al-doped films, including a lower chemical reactivity, a greater resistance to oxygen, and a lower moisture resistance. Furthermore, the radius of $\mathrm{Ga}$ ions $(0.062 \mathrm{~nm})$ is closer to that of $\mathrm{Zn}$ ions $(0.074 \mathrm{~nm})$ than that of $\mathrm{Al}$ ions $(0.053 \mathrm{~nm})[12,13]$. In addition, the covalent bond length of $\mathrm{Ga}-\mathrm{O}(1.92 \mathrm{~A})$ is smaller than that of $\mathrm{Zn}-\mathrm{O}(1.97 \mathrm{~A})$. As a result, minimal distortion of the doped $\mathrm{ZnO}$ lattice occurs, even in the case of a high Ga concentration. It has been shown that the addition of titanium (Ti) to the $\mathrm{ZnO}$ lattice is also of benefit in improving the electrical properties of $\mathrm{ZnO}$ thin films. However, the effects of $\mathrm{Ti}$ addition on the optoelectrical performance of Ga-doped $\mathrm{ZnO}(\mathrm{GZO})$ thin films have received little attention in the literature.

Many techniques are available for the deposition of $\mathrm{ZnO}$ based films on different substrates, including spray pyrolysis [14], metal organic chemical vapor deposition (MOCVD) [15], reactive RF-magnetron sputtering [16], pulsed laser deposition (PLD) [17], thermal oxidation [18], molecular beam epitaxy (MBE) [19] and sol-gel [20]. Of these techniques, RF-magnetron sputtering is generally preferred for 
the deposition of $\mathrm{ZnO}$ films on large-scale substrates due to the high cleanness and easily controlled composition [21].

In the present study, the RF-magnetron sputtering technique is used to deposit Ti-doped GZO thin films on glass substrates. The thin films are then annealed at temperatures of $300^{\circ} \mathrm{C}, 500^{\circ} \mathrm{C}$, and $550^{\circ} \mathrm{C}$, respectively. The effects of the annealing temperature on the optical properties, resistivity, and nanomechanical properties of the Ti:GZO thin films are then systematically explored.

\section{Experimental Procedure and Material Preparation}

The Ti:GZO thins films were deposited in an argon environment using an RF-magnetron sputtering system containing a Ga: $\mathrm{ZnO}$ alloy target (2-inch diameter) comprising sintered GZO pellets $\left(3 \% \mathrm{Ga}_{2} \mathrm{O}_{3}\right.$ mixed with $\mathrm{Ga}_{2} \mathrm{O}_{3}$ (99.9\%) and $\mathrm{ZnO}(99.2 \%)$ ) and a Ti target (4-inch diameter, consisting of sintered high-purity Ti metal powder (99.9\%)).

The Ti:GZO thin films were deposited on $2.0 \times 2.0 \mathrm{~cm}$ Cornings glass substrates using an RF power of $60 \mathrm{~W}$ for the Ga:ZnO target and a DC power of $60 \mathrm{~W}$ for the Ti target. Prior to the sputtering process, the substrates were cleaned ultrasonically in acetone and methanol and were then dried in a high-pressure flow of nitrogen gas. The distance between each target and the substrate was set as $8 \mathrm{~cm}$. The gas flow and working pressure of the Argon gas were set as $10 \mathrm{sccm}$ and $10^{-5}$ torr, respectively. In preparing the Ti:GZO thin films, a thin $\mathrm{Ti}$ layer was first sputtered on the glass substrate and a GZO film was then deposited on the Ti film. The average thickness of Ti:GZO thin films is $230 \mathrm{~nm}$. Following the deposition process, the thin-film structures were annealed at temperatures of $300^{\circ} \mathrm{C}, 500^{\circ} \mathrm{C}$, and $550^{\circ} \mathrm{C}$, respectively.

The microstructural characteristics of the as-deposited and annealed thin-film structures were investigated by Xray diffraction (XRD, SIEMENS D5000). Meanwhile, the resistivity of the thin films was measured using a fourprobe instrument. The carrier concentration and Hall mobility were estimated by a Hall effect analyzer (AHM-800B). The transmittance spectra of the Ti:GZO thin films were measured for wavelengths in the range of 300 1000 nm using a UV-VIS spectrophotometer (Hitachi U-4001). The surface morphology of each film was observed via scanning electron microscopy (SEM, FEI Quanta 400 F). Finally, the nanomechanical properties of the Ti:GZO films were measured using an MTS Nanoindenter XP system fitted with a Berkovich diamond pyramid tip.

\section{Results and Discussions}

3.1. Effect of Annealing Temperature on Structural Properties of Ti:GZO Thin Films. Figure 1 shows the XRD spectra of the as-deposited Ti:GZO thin film and the Ti:GZO thin films annealed at temperatures of $300^{\circ} \mathrm{C}, 500^{\circ} \mathrm{C}$, and $550^{\circ} \mathrm{C}$, respectively. It is seen that all of the films have a strong (002) diffraction peak located at around $2 \theta=34.3^{\circ}$. The diffraction peak is located close to that of pure $\mathrm{ZnO}$ crystal (34.45). Thus, it is inferred that the GZO thin film retains

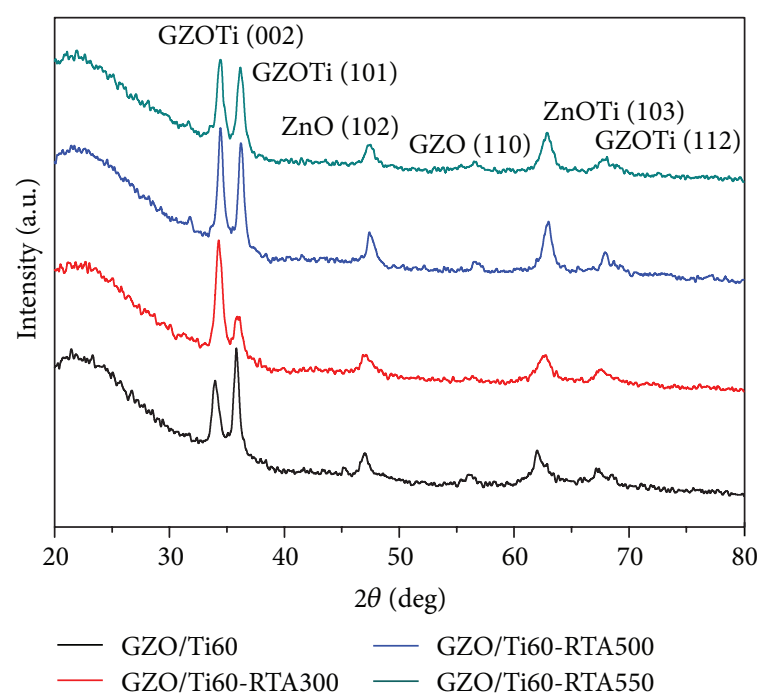

FIGURE 1: XRD spectra of Ti:GZO thin films annealed at different temperatures.

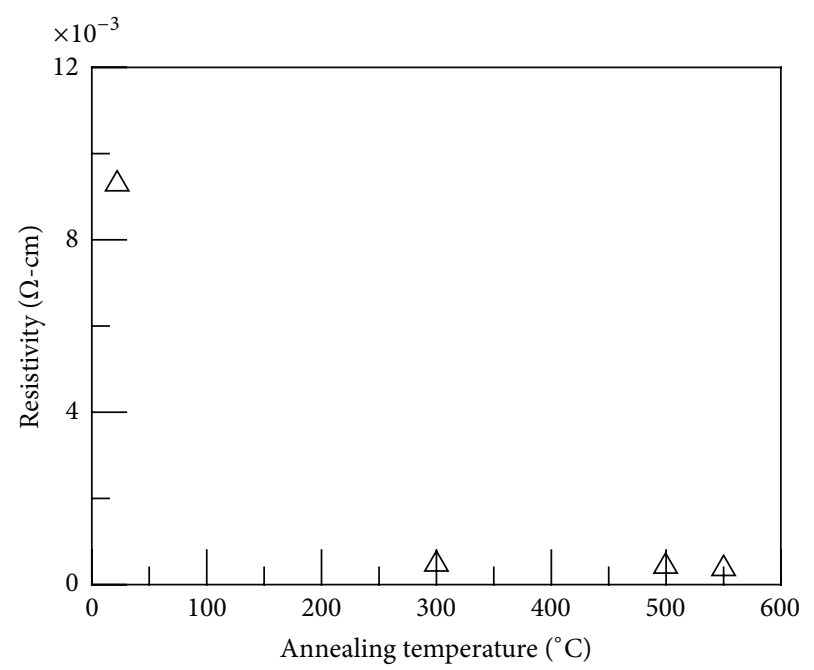

FIgURE 2: Variation of Ti:GZO thin film resistivity with annealing temperature.

the original characteristics of the hexagonal $\mathrm{ZnO}$ wurtzite; that is, the $\mathrm{Ga}$ content of the thin film segregates to that of the $\mathrm{Ti}$ and $\mathrm{Ga}$ contents of the thin film segregate to the noncrystalline region of the lattice at the grain boundaries [22]. It is noted that the intensity of the diffraction peak increases with an increasing annealing temperature. In other words, the crystallinity is fine at higher values of the annealing temperature.

\subsection{Effect of Annealing Temperature on Electrical Properties of} Ti:GZO Thin Films. Figure 2 shows the electrical resistivities of the as-deposited and annealed Ti:GZO thin films. The electrical resistivities for as-deposited $\left(25^{\circ} \mathrm{C}\right), 300^{\circ} \mathrm{C}, 500^{\circ} \mathrm{C}$, and $550^{\circ} \mathrm{C}$ are $9.37 \times 10^{-3} \Omega-\mathrm{cm}, 5.24 \times 10^{-4} \Omega-\mathrm{cm}, 5 \times 10^{-4} \Omega$ $\mathrm{cm}$, and $4.32 \times 10^{-4} \Omega-\mathrm{cm}$, respectively. As the annealing 
temperature is increased from $25^{\circ} \mathrm{C}$ to $550^{\circ} \mathrm{C}$, the resistivity reduces from $9.37 \times 10^{-3}$ to $4.32 \times 10^{-4} \Omega-\mathrm{cm}$. The reduction in resistivity is the result of various factors, including an improved crystallinity, a reduced grain boundary scattering of the charge carriers, an increased substitutional doping, and a reduced number of interstitial atoms. In addition, it was argued in [23] that an increased annealing temperature improves the ability of the Ti atoms to diffuse into the GZO thin film, thereby increasing the free carrier concentration and reducing the resistivity. Figure 3 shows the variation of the carrier electron concentration and the Hall mobility of the Ti:GZO films with the annealing temperature. It is seen that the carrier electron concentration and Hall mobility both increase with an increasing annealing temperature. The greater concentration of free carrier electrons increases the conductivity of the Ti:GZO thin film. Thus, as shown in Figure 2, the resistivity of the thin films reduces as the annealing temperature is increased.

3.3. Effect of Annealing Temperature on Optical Properties of Ti:GZO Thin Films. Figure 4 shows the transmission spectra of the as-deposited and annealed Ti:GZO thin films for wavelengths ranging from 300 to $1000 \mathrm{~nm}$. It is seen that the average transmittance of the as-deposited Ti:GZO thin film is around $70 \%$. However, the transmittance increases to around $86 \%$ and $88 \%$ in the annealed temperatures of $300^{\circ} \mathrm{C}$ and $500^{\circ} \mathrm{C}$, respectively. The increased transmittance at higher annealing temperatures is the result of a greater diffusion of the Ti atoms into the GZO film. From inspection, the maximum transmittance is found to be $\sim 92 \%$ for the Ti:GZO film annealed at the highest temperature of $550^{\circ} \mathrm{C}$.

\subsection{Effect of Annealing Temperature on Surface Morphology} of Ti:GZO Thin Films. Figure 5 presents the EDX analysis results for the as-deposited Ti:GZO thin film. The results confirm the diffusion of Ti atoms into the thin GZO film during the deposition process. Figure 6(a) shows the surface morphology of the as-deposited Ti-GZO thin film. It can be seen that the film has a pebble-like morphology with an average grain size of around $80 \mathrm{~nm}$. For the thin film annealed at a temperature of $300^{\circ} \mathrm{C}$, the average grain size increases to around $100 \mathrm{~nm}$ as the result of an enhanced crystalline growth rate (Figure 6(b)). The grain size continues to increase with an increasing annealing temperature, giving rise to grain sizes of around $105 \mathrm{~nm}$ and $110 \mathrm{~nm}$ in the films annealed at temperatures of $500^{\circ} \mathrm{C}$ and $550^{\circ} \mathrm{C}$, respectively (Figures $6(\mathrm{c}$ ) and 6(d)).

\subsection{Effect of Annealing Temperature on Nanomechanical Prop-} erties of Ti:GZO Thin Films. Figure 7(a) shows the typical load displacement curves obtained during the nanoindentation tests for the as-deposited and annealed Ti-GZO films, respectively. In general, the results show that the annealed films have both a higher hardness and a greater elasticity than the as-deposited film [21]. Figures 7(b) and 7(c) show the hardness and Young's modulus values of the as-deposited and annealed films as a function of the penetration depth. It is

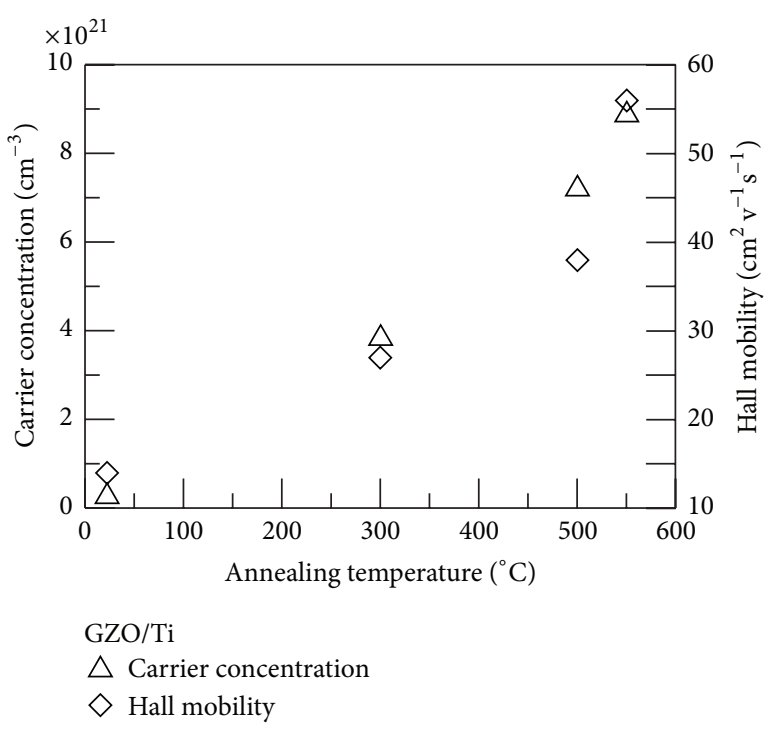

FIGURE 3: Variation of carrier electron concentration and Hall mobility of Ti:GZO thin films as function of annealing temperature.

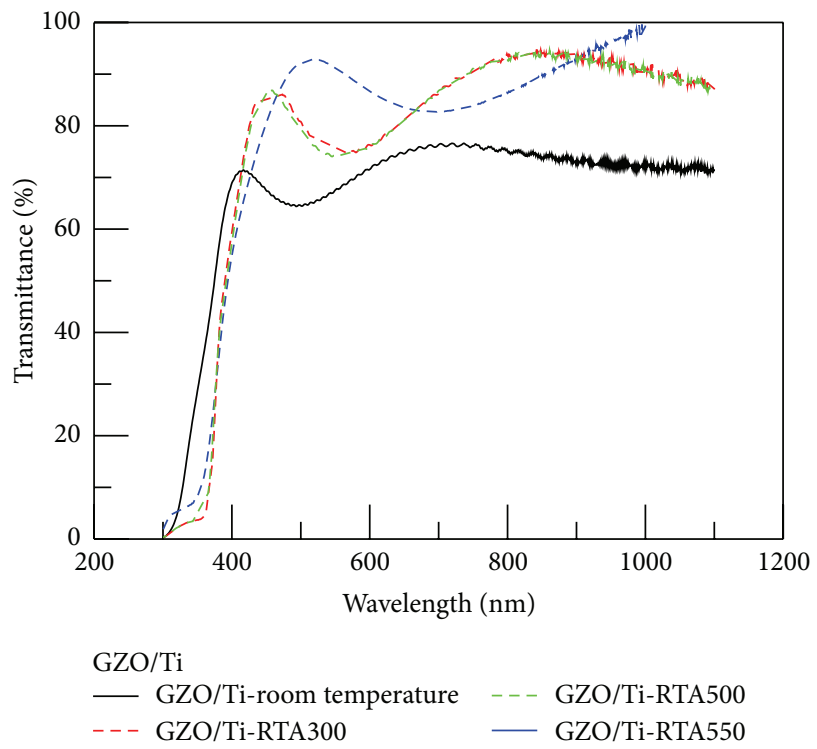

FIGURE 4: Transmission spectra of Ti:GZO thin films annealed at different temperatures.

seen that for all of the films, the hardness and Young's modulus increase rapidly with an increasing penetration depth before reaching a peak value and then gradually reducing slightly toward an approximately constant value. The results presented in Figure 7 show that the hardness of the Ti-GZO films increases from $7.9 \mathrm{GPa}$ in the as-deposited condition to 8.9 GPa in the annealed $\left(550^{\circ} \mathrm{C}\right)$ condition. Similarly, Young's modulus increases from $82 \mathrm{GPa}$ in the as-deposited thin film to $112 \mathrm{GPa}$ in the film annealed at $550^{\circ} \mathrm{C}$. In other words, both the hardness and Young's modulus of the Ti-GZO thin films increase with an increasing annealing temperature. As described in Section 3.4, the grain size of the Ti:GZO thin films increases with an increasing annealing temperature. 


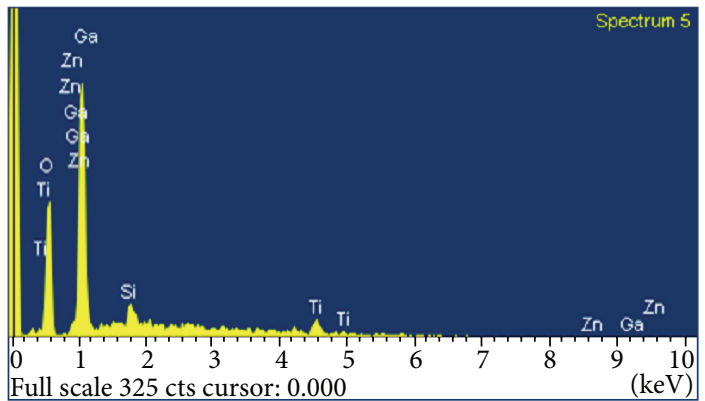

\begin{tabular}{|c|c|}
\hline Element & Weight (\%) \\
\hline O K & 27.51 \\
\hline Si K & 3.29 \\
\hline Ti K & 9.39 \\
\hline Zn L & 56.50 \\
\hline Ga L & 3.30 \\
\hline Totals & 100.00 \\
\hline
\end{tabular}

FIGURE 5: EDAX analysis of as-deposited Ti:GZO thin film.

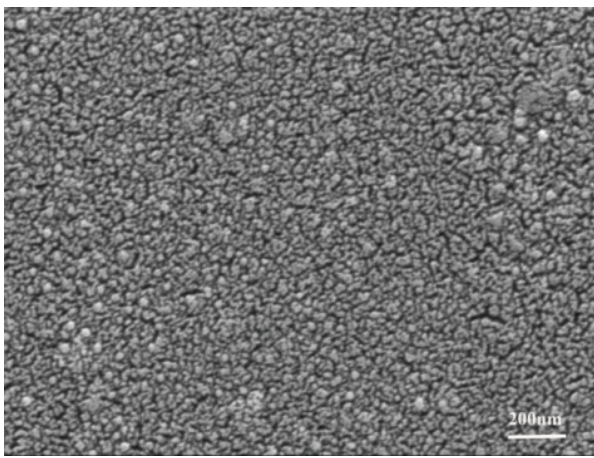

(a)

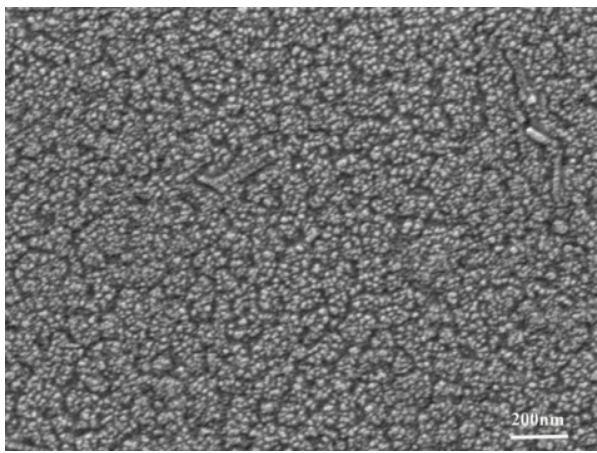

(c)

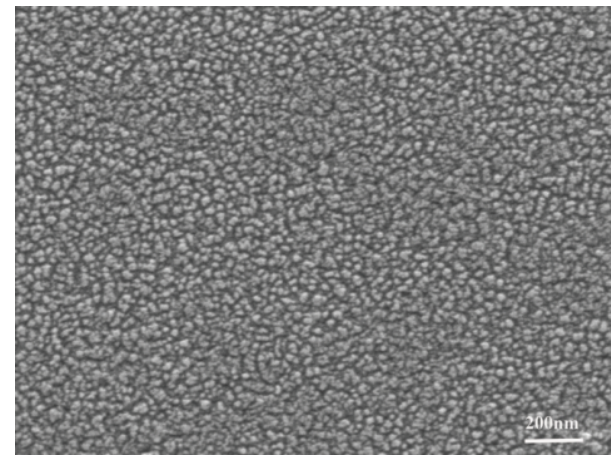

(b)

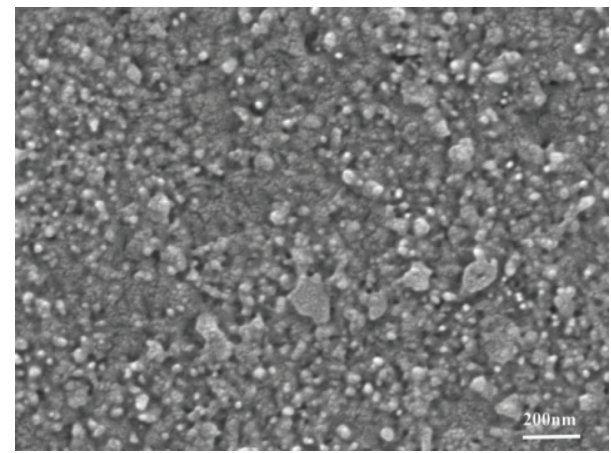

(d)

FIGURE 6: Surface morphologies of Ti:GZO thin films in (a) as-deposited condition and following annealing at (b) $300^{\circ} \mathrm{C}$; (c) $500^{\circ} \mathrm{C}$; and (d) $550^{\circ} \mathrm{C}$.

Thus, it can be inferred that the enhanced nanomechanical properties observed in the specimens annealed at a greater temperature can be attributed to the inverse Hall-Petch effect [24]. In general, the results presented in Figure 7 confirm the findings of Wang and $\mathrm{Li}[25]$ that the annealing temperature affects not only the optoelectrical properties of TCO thin films but also the nanomechanical properties.

\section{Conclusions}

Ti-doped GZO thin films have been deposited on glass substrates using an RF-magnetron sputtering technique and then annealed at temperatures of $300^{\circ} \mathrm{C}, 500^{\circ} \mathrm{C}$, and $550^{\circ} \mathrm{C}$, respectively. The XRD analysis results have shown that all of the films (as-deposited and annealed) have a hexagonal structure. Moreover, it has been shown that the resistivity of the Ti-GZO films reduces with an increasing annealing temperature as the result of an enhanced free carrier electron concentration and the Hall mobility. The results have shown that the annealing process increases the transmittance of the Ti-GZO films from around 70\% in the as-deposited condition to around $90 \%$ in the annealed condition as a result of the enhanced diffusion of $\mathrm{Ti}$ atoms into the GZO film. Finally, it has been shown that the annealing process improves both the hardness and the elasticity of the Ti-GZO thin films. Overall, the results presented in this study demonstrate that the optical, electrical, and nanomechanical properties of thin Ti-GZO films can all be improved through an appropriate postprocessing annealing operation. 


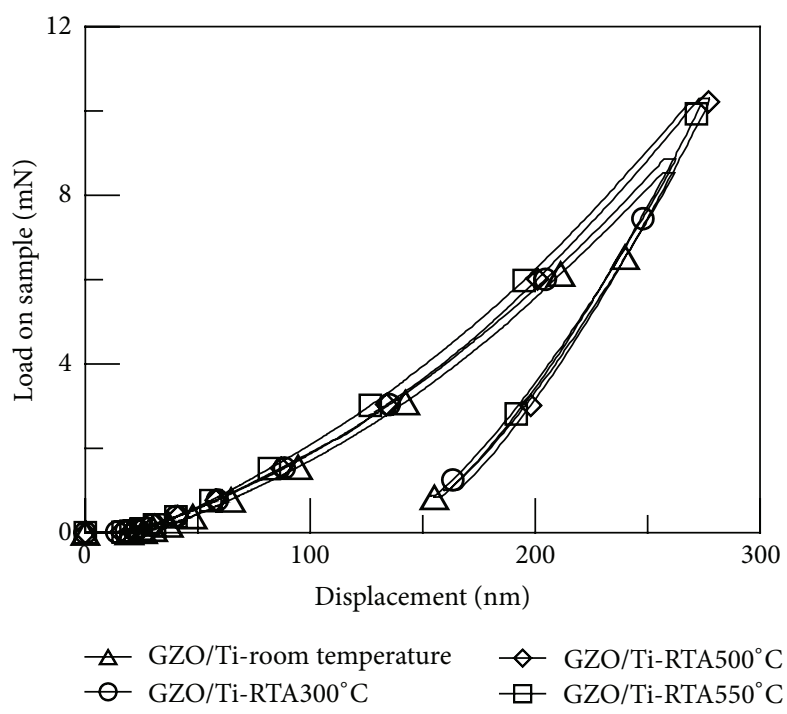

(a)

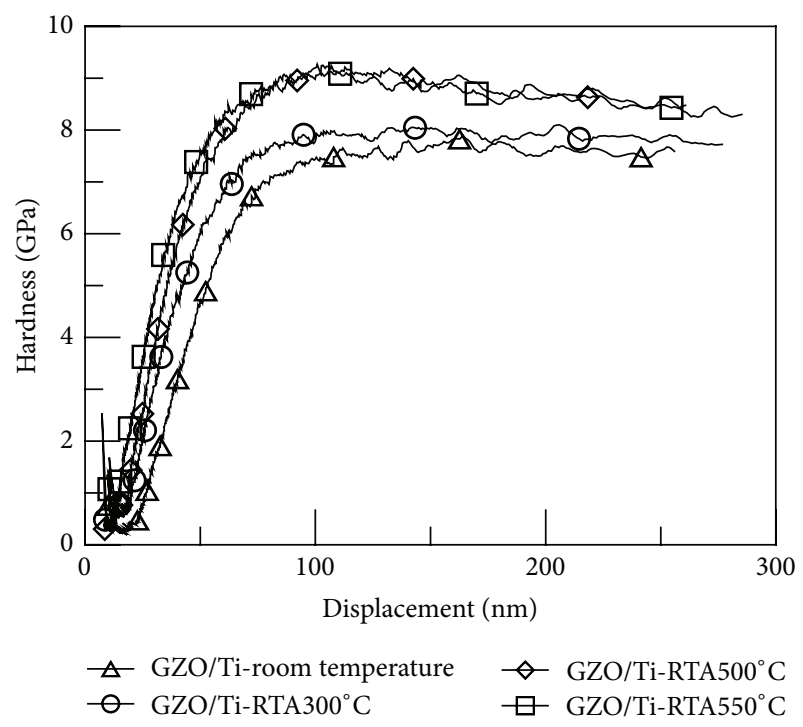

(b)

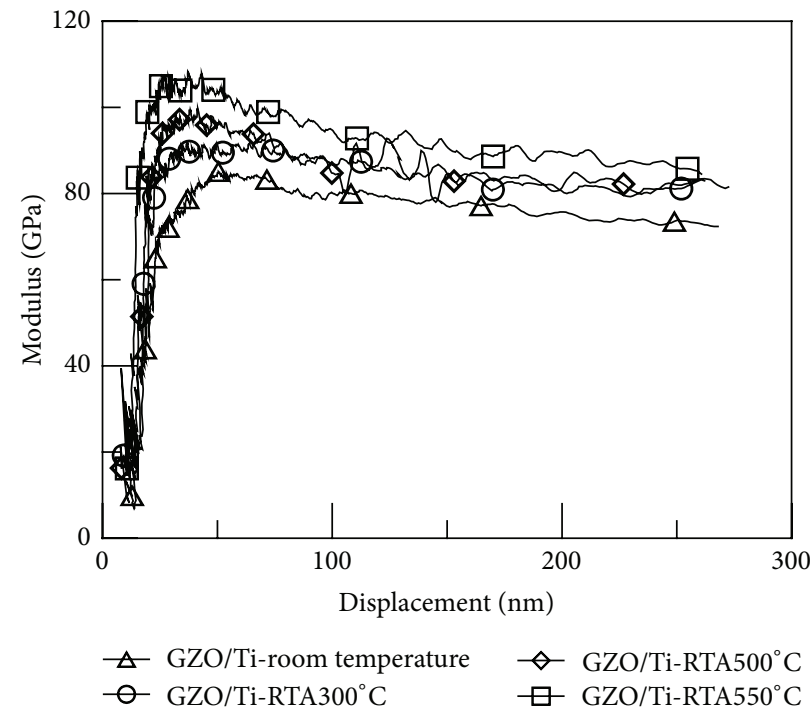

(c)

FIGURE 7: Nanomechanical response of as-deposited and annealed Ti:GZO thin films: (a) load displacement curves, (b) hardness curves, and (c) Young's modulus curves.

\section{Acknowledgment}

The authors gratefully acknowledge the financial support provided to this study by the National Science Council (NSC) of Taiwan under Contract no. NSC 99-2218-E-151-006-MY2.

\section{References}

[1] S.-J. Park, T.-Y. Park, Y.-S. Choi et al., "Enhanced optical power and low forward voltage of GaN-based light-emitting diodes with Ga-doped $\mathrm{ZnO}$ transparent conducting layer," Applied Physics Letters, vol. 96, no. 5, Article ID 051124, 2010.

[2] M. K. Puchert, A. Hartmann, R. N. Lamb, and J. W. Martin, "Highly resistive sputtered $\mathrm{ZnO}$ films implanted with copper," Journal of Materials Research, vol. 11, no. 10, pp. 2463-2469, 1996.
[3] S. Kobayakawa, Y. Tanaka, and A. Ide-Ektessabi, "Characteristics of $\mathrm{Al}$ doped zinc oxide (ZAO) thin films deposited by RF magnetron sputtering," Nuclear Instruments and Methods in Physics Research B, vol. 249, no. 1-2, pp. 536-539, 2006.

[4] M. L. Addonizio and C. Diletto, "Doping influence on intrinsic stress and carrier mobility of LP-MOCVD-deposited $\mathrm{ZnO}: \mathrm{B}$ thin films," Solar Energy Materials and Solar Cells, vol. 92, no. 11, pp. 1488-1494, 2008.

[5] J. J. Berry, D. S. Ginley, and P. E. Burrows, "Organic light emitting diodes using a Ga: $\mathrm{ZnO}$ anode," Applied Physics Letters, vol. 92, no. 19, Article ID 193304, 2008.

[6] Y. G. Wanga, S. P. Laua, X. H. Zhangb et al., "Enhancement of near-band-edge photoluminescence from $\mathrm{ZnO}$ films by face-toface annealing," Journal of Crystal Growth, vol. 259, pp. 335-342, 2003. 
[7] H. Sheng, N. W. Emanetoglu, S. Muthukumar, B. V. Yakshinskiy, S. Feng, and Y. Lu, "Ta/Au ohmic contacts to n-type $\mathrm{ZnO}$," Journal of Electronic Materials, vol. 32, no. 9, pp. 935-938, 2003.

[8] Y. R. Ryu, S. Zhu, D. C. Look, J. M. Wrobel, H. M. Jeong, and H. W. White, "Synthesis of p-type ZnO films," Journal of Crystal Growth, vol. 216, no. 1, pp. 330-334, 2000.

[9] H.-K. Kim, K.-K. Kim, S.-J. Park, T.-Y. Seong, and I. Adesida, "Formation of low resistance nonalloyed Al/Pt ohmic contacts on n-type $\mathrm{ZnO}$ epitaxial layer," Journal of Applied Physics, vol. 94, no. 6, pp. 4225-4227, 2003.

[10] J.-Y. Tseng, Y.-T. Chen, M.-Y. Yang et al., "Deposition of lowresistivity gallium-doped zinc oxide films by low-temperature radio-frequency magnetron sputtering," Thin Solid Films, vol. 517, no. 23, pp. 6310-6314, 2009.

[11] C. Guillén and J. Herrero, "High conductivity and transparent $\mathrm{ZnO}$ :Al films prepared at low temperature by DC and MF magnetron sputtering," Thin Solid Films, vol. 515, no. 2, pp. 640643, 2006.

[12] G. K. Paul and S. K. Sen, "Sol-gel preparation, characterization and studies on electrical and thermoelectrical properties of gallium doped zinc oxide films," Materials Letters, vol. 57, no. 3, pp. 742-746, 2002.

[13] C.-F. Yu, S.-H. Chen, S.-J. Sun, and H. Chou, "Influence of the grain boundary barrier height on the electrical properties of Gallium doped ZnO thin films," Applied Surface Science, vol. 257, no. 15, pp. 6498-6502, 2011.

[14] K. H. Yoon and J. Y. Cho, "Photoluminescence characteristics of zinc oxide thin films prepared by spray pyrolysis technique," Materials Research Bulletin, vol. 35, no. 1, pp. 39-46, 2000.

[15] J. Ye, S. Gu, S. Zhu et al., "The growth and annealing of single crystalline $\mathrm{ZnO}$ films by low-pressure MOCVD," Journal of Crystal Growth, vol. 243, no. 1, pp. 151-156, 2002.

[16] Q. P. Wang, D. H. Zhang, Z. Y. Xue, and X. J. Zhang, "Mechanisms of green emission from $\mathrm{ZnO}$ films prepared by rf magnetron sputtering," Optical Materials, vol. 26, no. 1, pp. 23-26, 2004.

[17] S. H. Bae, S. Y. Lee, H. Y. Kim, and S. Im, "Effects of postannealing treatment on the light emission properties of $\mathrm{ZnO}$ thin films on Si," Optical Materials, vol. 17, no. 1-2, pp. 327-330, 2001.

[18] Y. G. Wang, S. P. Lau, X. H. Zhang et al., "Evolution of visible luminescence in $\mathrm{ZnO}$ by thermal oxidation of zinc films," Chemical Physics Letters, vol. 375, no. 1-2, pp. 113-118, 2003.

[19] K. Sakurai, M. Kanehiro, K. Nakahara, T. T. Tetsuhiro Tanabe, S. Fujita, and S. Fujita, "Effects of oxygen plasma condition on MBE growth of ZnO," Journal of Crystal Growth, vol. 209, no. 2-3, pp. 522-525, 2000.

[20] D. G. Baik and S. M. Cho, "Application of sol-gel derived films for $\mathrm{ZnO} / n$-Si junction solar cells," Thin Solid Films, vol. 354, no. 1, pp. 227-231, 1999.

[21] S. R. Jian, G. J. Chen, S. K. Wang et al., "Rapid thermal annealing effects on the structural and nanomechanical properties of Gadoped ZnO thin films," Surface and Coatings Technology, 2012.

[22] X. Yu, J. Ma, F. Ji et al., "Preparation and properties of $\mathrm{ZnO}: \mathrm{Ga}$ films prepared by r.f. magnetron sputtering at low temperature," Applied Surface Science, vol. 239, no. 2, pp. 222-226, 2005.

[23] Z.-Z. Li, Z.-Z. Chen, W. Huang, S.-H. Chang, and X.-M. Ma, "The transparence comparison of Ga- and Al-doped $\mathrm{ZnO}$ thin films," Applied Surface Science, vol. 257, no. 20, pp. 8486-8489, 2011.
[24] J. Schiøtz, T. Vegge, F. D. Di Tolla, and K. W. Jacobsen, "Atomic-scale simulations of the mechanical deformation of nanocrystalline metals," Physical Review B, vol. 60, no. 17, pp. 11971-11983, 1999.

[25] G. Wang and X. Li, "Size dependency of the elastic modulus of ZnO nanowires: surface stress effect," Applied Physics Letters, vol. 91, no. 23, Article ID 231912, 2007. 

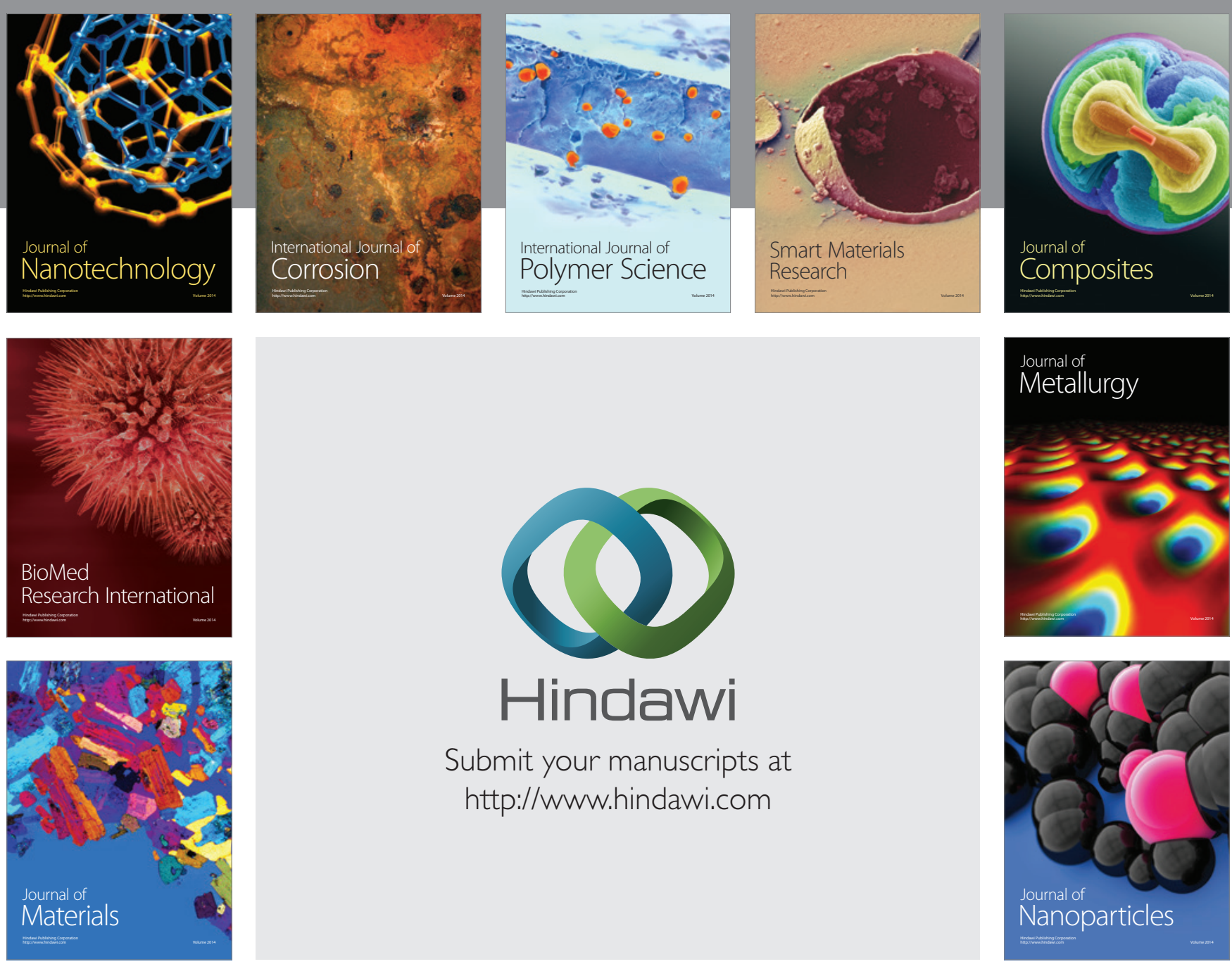

Submit your manuscripts at http://www.hindawi.com
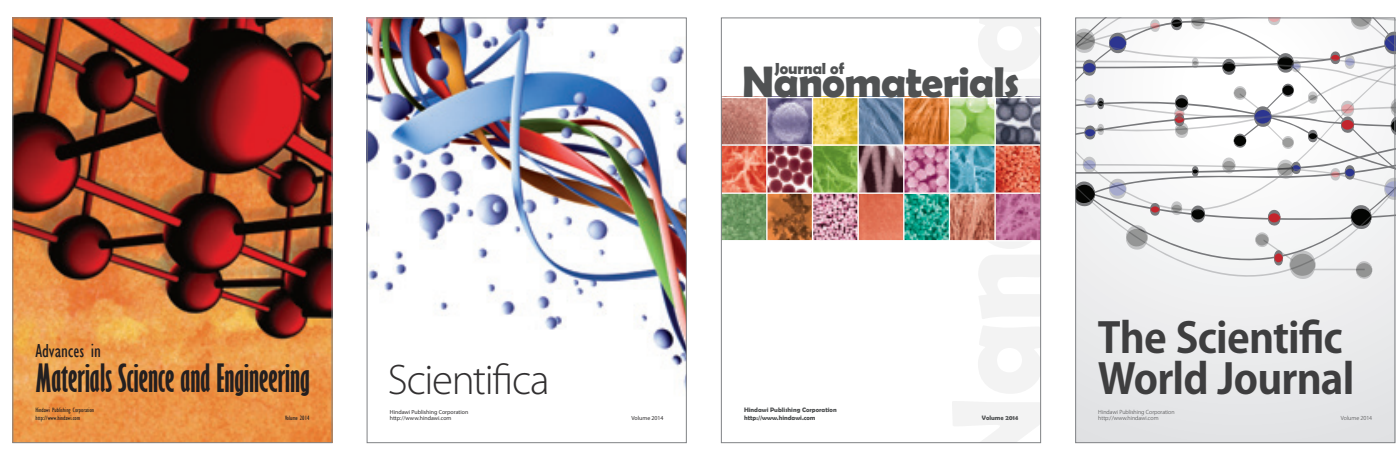

\section{The Scientific World Journal}
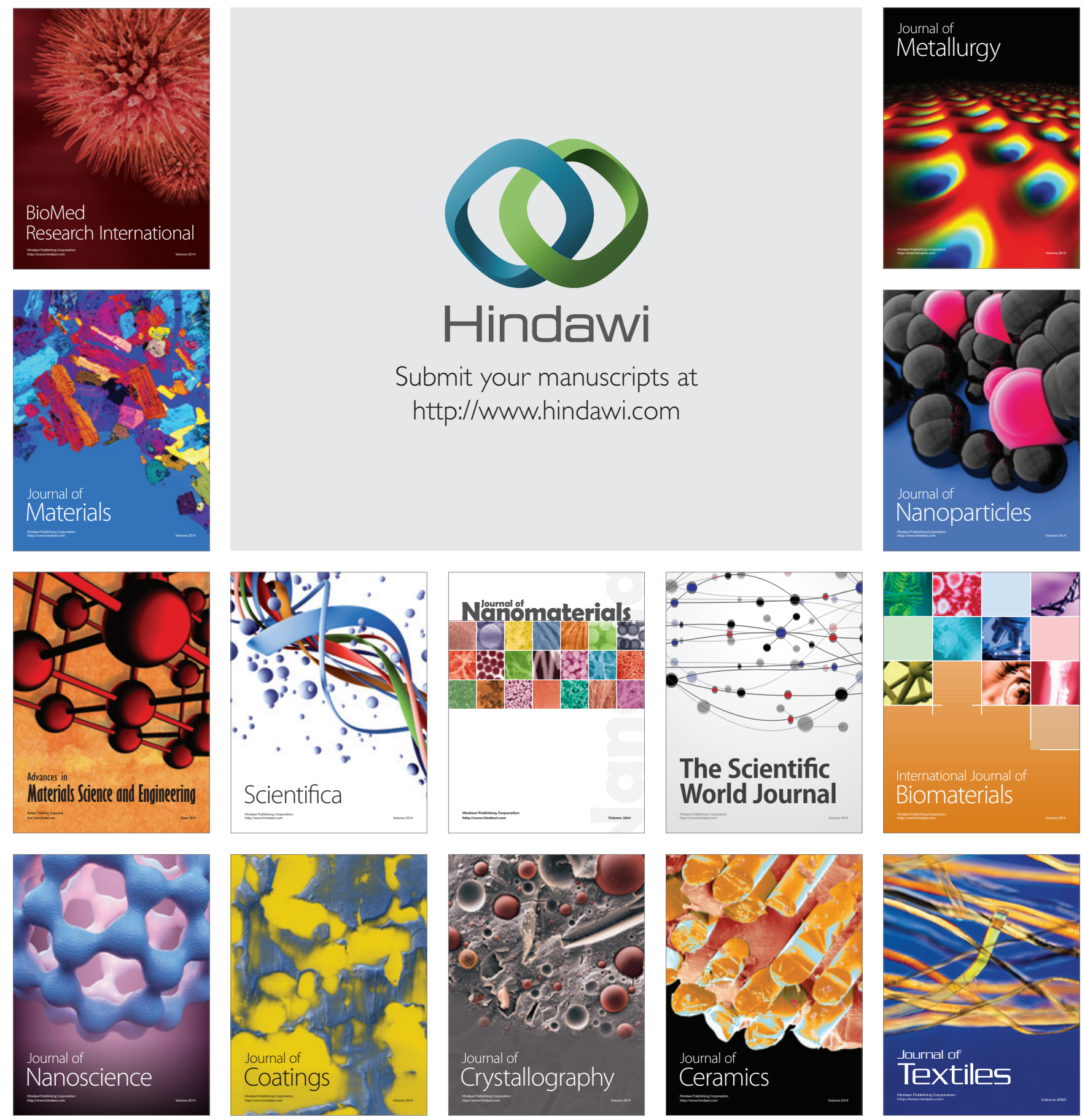